\title{
TO TREAT OR TO SATISFY THE PATIENT; WHICH ONE IS THE BEST?
}

\section{Thamer A Hamdan}

MB,ChB, FRCS, FICS, FACS, American Board, Professor of Orthopedic Surgery, Chancellor of Basrah University, Basrah, IRAQ.

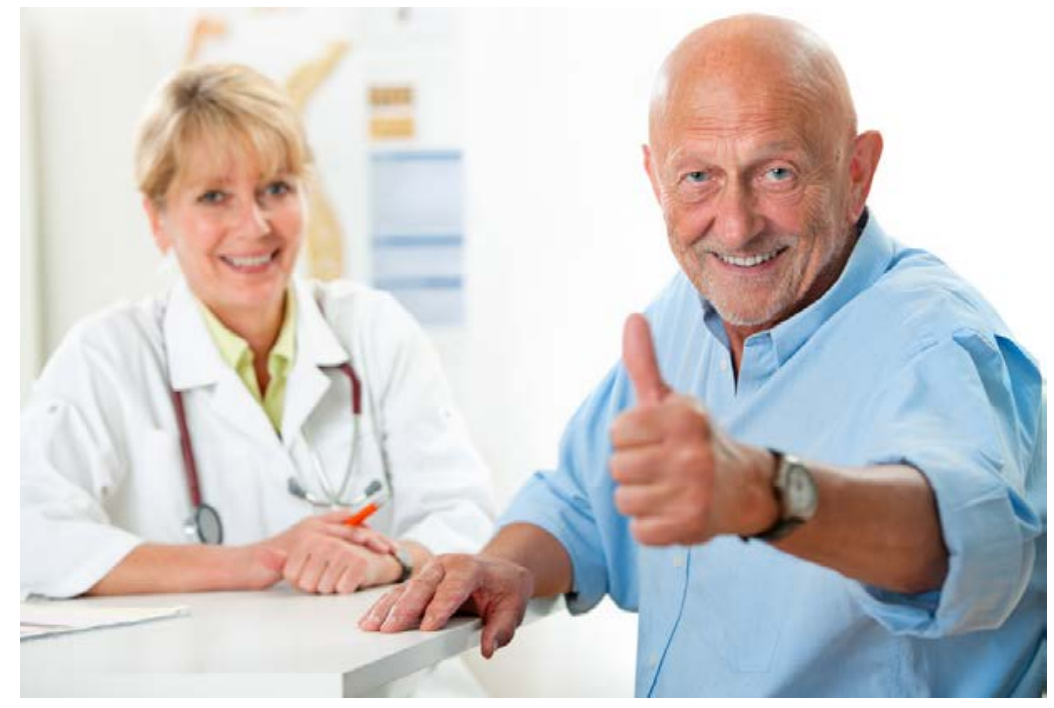

$\mathrm{L}$ uckily, there is increasing interest in patient satisfaction in the present days. Many writers started differentiating between the two issues; treatment or satisfaction. Patient satisfaction is a top priority and it should be the target. Perfect treatment is not always satisfactory to the patient. Some surgeons, sadly, spoil their ideal treatment by misconduct. They are good enough to offer treatment, but not good enough in performing the art of communication, which is really vital. They do not know how to respect the dignity, the honor and rights of the patient. The first meeting is the key for success in achieving life-long friendship or, on the other hand "putting salt on the wound"

The art of patient handling is not that easy. Surgeon's words, sometimes, create emergency, probably much more serious than the surgeon's knife. What looks minor to the surgeon, may be enough to make the patient complaining bitterly.

Several points and steps are, therefore, required to achieve appropriate satisfaction. As cited above, performing highly skilled and perfect surgery is not enough to satisfy the patient, since satisfaction is a complex issue that depends on several parameters. Sound judgment, high index of patient selection, surgeon's behavior, sympathy and empathy, feeling patient's suffering, and surgeon's skills are all required.

The surgeon's behavior is the key for success or failure. He is the first to be blamed even for problems not related to him, because, in the patient's mind, he is considered to be the leader.

In addition, the administrative and paper works, patient's transportation, the buildings and sanitary facilities, and the ward environment; how clean and fresh it is, all are basic 
requirements for satisfaction in the mind of patients and their escorts. Moreover, the nursing staff; how they handle the patient and how they follow the patient status, are also another factor contributing to patient's satisfaction. They should be very sympathetic in all aspects.

Listening to patient's suffering is very vital, and is required from all partners in the treatment team. Some pathological processes require prolonged treatment and may be associated with prolonged suffering. So, proper handling and utmost care is mandatory. We have to treat the patient psyche before treating the physical illness. No way of showing or using any pattern of force. It is very irritating even if ideal treatment is offered. A smooth, quiet and comforting words are mandatory.

The structure and design of the accommodation, also, have an impact on the patient's mind. Some patients need very special handling, like those who are already psychologically traumatized, those with incurable conditions, prolonged illnesses, recurrent pathologies, previous mishandling or those who are badly treated by other colleagues. All the above may be troublesome and very difficult to satisfy. Patients' escorts are, sometimes, worse than patients themselves.

Alleviating pain, by any mean, will induce confidence and satisfaction; also relieving other symptoms like fever, diarrhea, or vomiting. Prolonged waiting list will induce fed up, and necessitates cares on behalf of the surgeon and the hospital.

Age and gender may make some difference in the patients satisfaction. In my experience, the teenager girls are not easy to satisfy.

In our locality, there is a break in the doctor-patient relationship which contributes, to a great extent, for not achieving satisfaction.

We have to work hard to improve our behavior towards our dear patients. Our handling of patients need revision. Courses are required to teach young generations how to behave to achieve satisfaction. A questionnaire is required to spot the weak points in handling patients before leaving the hospital. This will help very much. Follow up is part of the patient's treatment. It has a real impact on patient's satisfaction.

Finally, it is never enough to offer treatment alone. Satisfaction should go hand-in-hand with the ideal treatment.

Sadly, we are treating our dear patients, but how many times we have satisfy them?.
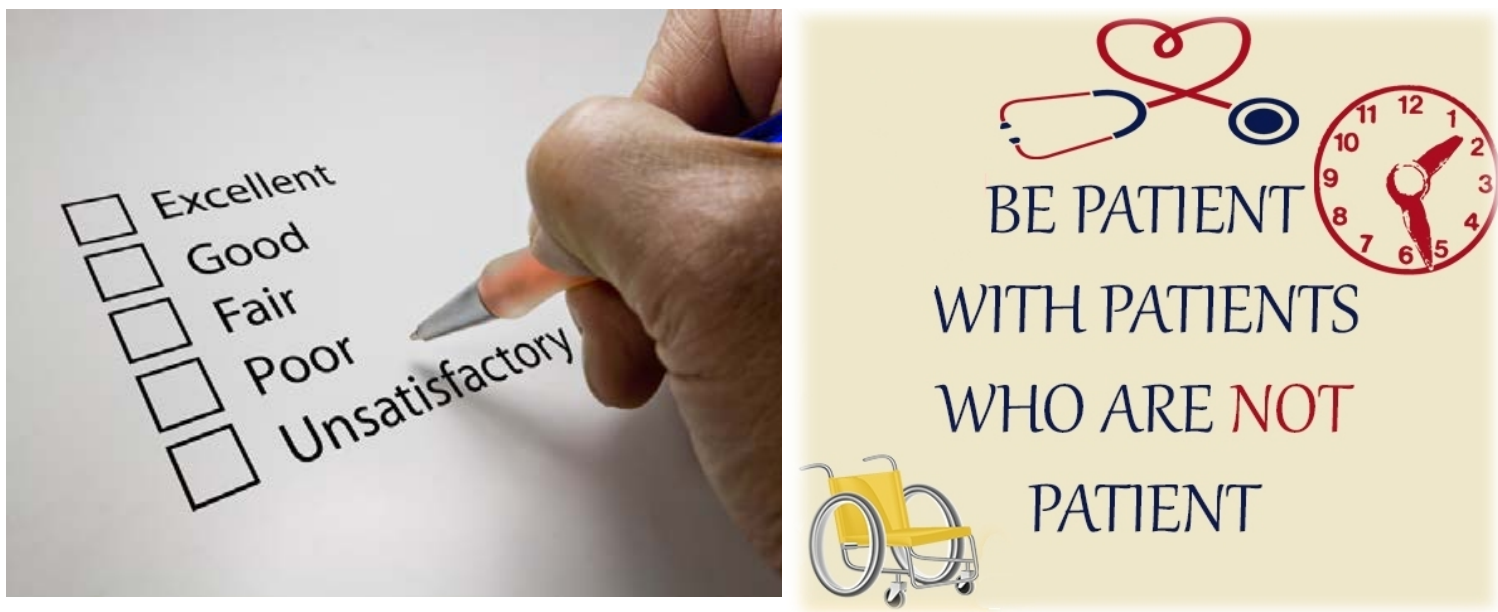